\title{
DEIKSIS PERSONA, DEIKSIS TEMPAT, DEIKSIS WAKTU DALAM NOVEL KIDUNG RINDU DI TAPAL BATAS KARYA AGUK IRAWAN MN
}

\author{
Sarpia Yunus, Dakia N Djou, Salam \\ Prodi Pendidikan Bahasa dan Sastra Indonesia, \\ Fakultas Sastra dan Budaya, Universitas Negeri Gorontalo \\ *coresponding yunussarpia@gmail.com \\ Universitas Negeri Gorontalo, dakiadjou.ung@gmail.com \\ Universitas Negeri Gorontalo, salamtolaki@ung.ac.id
}

\begin{abstract}
Abstrak
Penelitian ini bertujuan untuk mendeskripsikan penggunaan deiksis persona, deiksis tempat, dan deiksis waktu dalam novel Kidung Rindu di Tapal Batas karya Aguk Irawan MN. Metode penelitian yang digunakan yakni deskriptif dengan jenis kualitatif. Data penelitian yakni kutipan berupa kalimat-kalimat yang mengandung deiksis persona, deiksis tempat serta deiksis waktu dalam novel Kidung Rindu di Tapal Batas karya Aguk Irawan MN, dengan sumber data diperoleh dari novel Kidung Rindu di Tapal Batas karya Aguk Irawan MN serta dari beberapa literatur seperti jurnal dan juga buku, dan menggunakan teknik pengumpulan data yakni dengan teknik baca dan catat. Adapun teknik analisis data menggunakan empat tahap yakni mengidentifikasi, memilah, interpretasi, dan simpulan. Hasil penelitian ini menunjukkan bahwa penggunaan deiksis persona orang pertama menggunakan referen "saya" yang merujuk kepada Iskandar, Ibu, Ahmad Ibrahim, Nanjan, seorang lelaki, Felix dan Hasyim, sedangkan deiksis persona orang kedua menggunakan referen "kau" yang merujuk kepada Parno, Mamut, Iskandar, Rustam, Nanjan, Felix Nei, Cornelius, Siti, Kumar, Masyarakat Jagoi Babang, Imah, dan Sipet dan deiksis persona orang ketiga menggunakan referen "dia, ia" yang merujuk kepada Pang Ukir, Nanjan, Felix, Seorang lelaki, Rustam, Hamdan, Sukimin, Cornelius, Nei, Mamut, Jokowi, kakek, Siti Nur Azizah, pemerintah Malaysia dan sebuah bendera. Adapun dalam deiksis tempat menggunakan referen "di sini" yang merujuk terhadap Jagoi Babang, pos Perbatasan, Malaysia dan rumah Nanjan dan pengunaan referen "di sana" merujuk terhadap Jagoi Babang, Malaysia,dada manusia, pasar Serikin dan Suriname. Terkahir deiksis waktu menggunakan referen "hari ini", "Nanti malam", "dulu", "hari minggu". "kemarin", "minggu depan", dan "besok
\end{abstract}

Kata Kunci : deiksis persona, deiksi tempat, deiksis waktu, novel Kidung Rindu di Tapal Batas

\begin{abstract}
This research aimed to describe the usage of person deixis, spatial deixis, and temporal deixis in Kidung Rindu di Tapal Batas, a novel by Aguk Irawan MN. This descriptive research employed qualitative method. The research data comprised quotation forms. Data analysis was done in four steps; namely, identifying, sorting, interpreting, and concluding. The result showed that in the person deixis, the used first-person pronoun is " $I$ " which referred to Iskandar, the mother, Ahmad Ibrahim, Nanjan, a man, Felix, and Hasyim. For the second-person, its used pronoun is "you", which referred to Parno, Mamut, Iskandar, Rustam, Nanjan, Felix Nei, Cornelius, Siti, Kumar, the villagers of
\end{abstract}


Jagoi Babang, Imah, and Sipet. The used third-person pronouns are "he, she, it" which referred to Pang Ukir, Nanjan, Felix, characters that were not explained, Rustam, Hamdan, Sukimin, Cornelius, Nei, Mamut, Jokowi, grandpa, Siti Nur Azizah, the Malaysian Governmant, and flag. The spatial deixis used the adverb "here", which referred to Jagoi Babang, the border post, Malaysia, and Nanjian's home. Another used adverb is "there", which reffered to Jagoi Babang, Malaysia, human's chest, Serikin Market and Suriname. The last one is temporal deixis. It used the adverb "today", "tonight", "previously", "Sunday", "yesterday", "next week", and "tomorrow".

Keywords: Person Deixis, Spatial Deixis, Temporal Deixis, Kidung Rindu di Tapal Batas, Novel

\section{PENDAHULUAN}

Bahasa merupakan bentuk komunikasi baik lisan maupun tulisan. Penggunaan bahasa dalam konteks kehidupan sangatlah penting, sebab dengan bahasa setiap individu dapat saling bersosialisasi dan berinteraksi antara satu dengan yang lain. Sama halnya menurut Kridaklaksana (dalam Aminuddin, 2008:28) bahasa adalah sistem lambang yang dipergunakan suatu masyarakat untuk bekerja sama, berinteraksi, dan mengindektifikasi. Chaer (2012:51) mengatakan bahwa bahasa itu bersifat unik, maka artinya setiap bahasa memiliki ciri khas sendiri yang tidak dimiliki oleh bahasa lainnya. Salah satu kajian ilmu bahasa yang cukup populer adalah pragmatik. Pragmatik merupakan cabang ilmu linguistik yang mengkaji tentang bentuk-bentuk penggunaan bahasa serta sebagai bentuk komunikasi antara penutur dan mitra tutur. Pragmatik merupakan disiplin ilmu linguistik yang memaknai bahasa dalam bentuk komunikasi baik situasi yang bersifat nyata atau yang bersifat abstrak. Hermaji (2019:3) istilah pragmatik pertama kali digunakan oleh seorang filsuf (ahli filsafat) terkenal bernama Charles Mooris (1938).

Adapun salah satu aspek yang dapat dikaji dalam pragmatik yakni deiksis. Deiksis adalah sebuah kata yang menunjukkan sesuatu yang sifatnya tidak tetap atau berubah-ubah, sehingga untuk memahami kata tersebut harus disesuaikan dengan penutur serta mitra tutur dan konteks tuturan. Yule (2014:13) menjelaskan bahwa deiksis merupakan "penunjukan" melalui bahasa. Kata atau referen yang termasuk dalam deiksis pada hakikatnya selalu berubah-ubah. Deiksis sendiri terdiri dari beberapa jenis antara lain deiksis persona, deiksis tempat, deiksis waktu, deiksis sosial, deiksis wacana, dan deiksis penunjuk. Adapun jenis deiksis yang digunakan dalam penelitian ini adalah deiksis persona, deiksis tempat dan deiksis waktu. Ketiga deiksis deiksis merupakan deiksis utama dalam pengelompokan jenis-jenis deiksis. Oleh karena itu, peneliti lebih memfokuskan pada ketiga deiksis yakni deiksis persona, tempat, serta deiksis waktu. Penggunaan deiksis tidak hanya bisa dijumpai dalam proses komunikasi lisan saja, bentuk tulis pun banyak dijumpai penggunaan deiksis. Bentuk tulis yang menjadi titik fokus penelitian adalah sebuah karya sastra khususnya novel.

Novel menjadi salah satu karya sastra yang banyak menggunakan deiksis. Deiksis dalam novel pula memberikan petunjuk kepada setiap pembaca waktu dan tempat kejadian yang dialami oleh tokoh-tokoh yang diceritakan. Goldmann (dalam Wicaksono, 2014:70) mendefinisikan novel merupakan cerita mengenai pencarian yang terdegradasi akan nilai-nilai otentik di dalam dunia yang juga terdegradasi, pencarian itu dilakukan oleh seseorang hero yang problematik. 


\section{METODE}

Metode penelitian yang digunakan dalam penelitian ini adalah deskriptif dengan jenis penelitian kualitatif. Penelitian deskriptif kualitatif merupakan sebuah penelitian yang menggambarkan secara jelas bagaimana fenomena yang dijadikan sebagai objek kajian. Data dalam penelitian ini adalah data tertulis yakni kutipan-kutipan berupa kalimat yang mengandung deiksis persona, deiksis tempat, serta deiksis waktu dalam novel Kidung Rindu di Tapal Batas karya Aguk Irawan MN, dan sumber data yakni novel Kidung Rindu di Tapal Batas karya Aguk Irawan MN. Selain itu juga menggunakan sumber tertulis seperti, buku dan jurnal. Teknik pengumpulan data menggunakan teknik baca yaitu teknik baca skimming serta menggunakan teknik catat. Terakhir, adapun bentuk teknik analisis data sebagai berikut. Pertama, mengindektifikasi seluruh kata atau kalimat yang mengandung deiksis persona, deiksis tempat, dan deiksis waktu dalam novel Kidung Rindu di Tapal Batas karya Aguk Irawan MN. Kedua,memilah dan mengelompokkan kata atau kalimat yang termasuk dalam deiksis persona, deiksis tempat, dan deiksis waktu. Ketiga, interpretasi atau menganalisis data-data yang telah dikelompokkan. Keempat, simpulan setelah seluruh data diinterpretasi.

\section{HASIL DAN PEMBAHASAN}

\section{Deiksis Persona}

\section{Deiksis Persona Orang Pertama}

Deiksis persona orang pertama adalah deiksis yang lebih merujuk pada diri sendiri atau si penutur. Berdasarkan hasil pengumpulan data maka ditemukan beberapa penggunaan deiksis persona orang pertama yakni kata saya. Deiksis persona orang pertama ini pada dasarnya mengacu kepada diri si penutur itu sendiri.

Data 1

"Maafkan saya, Ki," ucap Iskandar segera, seperti menyesali dengan apa yang ia ucapkan.

Maafkan saya...."

"Kudengar," ucapan Pang Ukir seakan tak memedulikan permintaan maaf Iskandar,..."

(Irawan MN, 2015:13)

Kata saya dalam data di atas digunakan sebagai bentuk rujukan kepada si penutur, dalam hal ini Iskandar serta Pang Ukir sebagai mitra tutur. Bentuk penggunaan deiksis persona orang pertama ini didasari oleh perbedaan umur serta konteks sosial yang terjalin antara si penutur dan juga mitra tutur, karena pada hakikatnya penggunaan deiksis persona tidak serta merta langsung digunakan begitu saja, melainkan harus memperhatikan kedua aspek utama tersebut.

Data 2

"Hamdan, Ibu," ucap Hamdan.

"Nur Kamilah," jawab ibunya Siti. "Saya ibunya Siti."

"Iya, Bu."

"Nanda orang Melayu?"

"Iya, Bu. Saya orang Indonesia," jawab Hamdan, "dan Melayu."

"Ooo..."

(Irawan MN, 2015:209-210)

\section{$\underline{\text { Data } 3}$}


“Hamdan," ucap Hamdan sopan.

"Ahmad Ibrahim," ucap bapak Siti. "Saya ayahnya Siti."

"Iya, Pak."

"Kata ibunya Nanda orang Melayu?"

"Iya, Pak. Saya Melayu. Indonesia-Melayu."

"Ooo..."

(Irawan MN, 2015:213)

Penggunaan referen saya dalam data kedua digunakan oleh Nur Kamilah untuk merujuk kepada dirinya. Kemudian pada baris kelima referen saya digunakan oleh Hamdan yang digunakan untuk merujuk kepada dirinya sendiri pada kalimat " $I y a, B u$. Saya orang Indonesia," jawab Hamdan, "dan Melayu". Adanya perpindahan rujukan referen saya ini, disebabkan konteks tuturan itu diujarkan.

$\underline{\text { Data } 4}$

Nanjan lalu berkata, "Saudara sekalian, hadir di tengah-tengah kita Bang Hasyim. Dia orang NTB-ah, jangan tanya saya di mana NTB saya tidak tahu....." (Irawan MN, 2015:106)

Data 5

“....Saudara-Saudara nanti bisa mendapatkannya dari saya. Data-data ini sangat penting. Termasuk, bagaimana cara kita agar bisa secepatnya pindah ke sana, menjadi warga negra Malaysia. Saya membuka penuh rumah saya dua puluh empat jam untuk kedatangan Saudara-saudara saya..."

(Irawan MN, 2015:274-275)

Data 5 penggunaan referen saya dalam tuturan tersebut berjumlah empat kali. Dalam penggunaannya, referen saya merupakan bentuk deiksis persona orang pertama yang memiliki makna bahwa penutur memiliki tingkat sosial lebih rendah dari pada mitra tutur atau sebagai bentuk penghormatan penutur kepada mitra tutur, sebab penggunaan referen saya dalam sebuah tuturan mampu memberikan sebuah kesan hormat atau dalam istilah disebut honorifics yakni penggunaan bahasa yang bertujuan untuk menghormati orang tertentu.

Data 6

“.... Saya sendiri tidak pernah mengenal Rupiah sama sekali. Uang, yang kutahu, hanyalah Ringgit kita kesulitan mendapatkan pekerjaan di negeri sendiri, tetapi haruskah kita pindah warga kenegaraan demi mengatasi semua ini?"

"Saya setuju dengan perkataan Pak Felix," ucap seseorang, menyambut.

(Irawan MN, 2015:110-111)

Tindak tutur di atas melibatkan seorang lelaki Jagoi Babang yang bernama Felix bersama seseorang yang tidak diketahui namanya. Penggunaan referen saya menjadi bentuk kata rujukan pada pada diri penutur dan juga mitra tutur.

Data 7

"Semua sudah saya ceritakan," jawab Hasyim. "Semalam saya lari dan terus lari. Saya hanya memikirkan keselamatan saya. Tapi ternyata mereka terus mengejar saya. berkali-kali tembakan diletuskan...."

(Irawan MN, 2015:26)

Dari data di atas menunjukkan penggunaan deiksis persona orang pertama yakni penggunaan kata saya. Hal terjadi saat proses interaksi antara seorang lelaki dan juga seorang tentara. Penggunaan referen saya merujuk kepada penutur dalam hal ini adalah 


\section{Deiksis Persona Orang Kedua}

Data 1

"Kita harus bagaimana" Nanjan bertanya.

"Harus terus sembunyi,"Mamut menjawab.

"Kalau terjadi tembak-menembak?" Hamdan bertanya.

"Kita lari!" Sukimin menjawab.

"Kita bantu bang Iskandar dan Cornelius!" ucap Parno.

"Kau mau mati?" Nanjan bertanya.

"Tidak," jawab Parno.

(Irawan MN, 2015:33)

Data 2

"Siapa saja yang telah dihubunginya?" Nanjan bertanya pada Mamut, saat mereka tengah menyusuri jalan setapak yang sunyi, pulang dari perbatasan.

"Katanya semua rumah telah ia datangi."

“Termasuk diperkampungan Malayu dan Jawa itu?'

"Iya katanya begitu."

"kau dapat kabar dari mana?"

"Sukimin dan Parno yang bercerita...."

(Irawan MN, 2015:147)

Tindak tutur dalam data 1 melibatkan lima orang pemuda-pemuda Jagoi Babang. Dalam tindak tutur tersebut terdapat penggunaan referen kau yang di tuturkan oleh Nanjan yang bila diamati referen tersebut merujuk kepada Parno. Pada data 2 yang ditemukan adanya tindak tutur yang melibatkan teman sejawat yang melibatkan Nanjan serta Mamut, sehingga sangat tepat jika menggunakan referen kau untuk merujuk kepada lawan tutur.

$\underline{\text { Data } 3}$

....Lalu kepada Iskandar, Cornelius berseru, "Hai, Bung. Kau telepon itu presiden. Suruh ke sini! Jemput rakyatnya yang satu ini."

(Irawan MN, 2015:59)

Pada data ketiga ditemukan adanya penggunaan referen kau yang dituturkan oleh Cornelius yang merujuk kepada Iskandar yang dibuktikan dalam kalimat "Hai, Bung. Kau telepon itu presiden. Suruh ke sini! Jemput rakyatnya yang satu ini".

Data 4

....Rustam dididik dengan jiwa nasionalisme dan patriotisme. Jangan pernah bertanya tentang cinta tanah air kepada prajurit, kecuali kau akan dianggap orang bodoh dan tolol dengan pertanyaan yang seperti itu.

(Irawan MN, 2015:72)

Pengarang menggunakan referen kau sebagai bentuk rujukan kepada para pembaca novel Hal ini sebagai pembentukan keakraban antara pengarang dan pembaca, sehingga para pembaca merasa lebih santai, mudah untuk dipahami maksud dan tujuan dari pengarang.

Data 5

"....tetapi kata Nanjan, "Buat apa?"

"Agar kau pintar."

"Tanpa sekolah," jawab Nanjan, "aku sudah bisa mencari Ringgit." "..."

(Irawan MN, 2015:81) 
Data 6

"Nenek cinta Jagoi Babang?"

"Kau ini tanya apa?"

"Nenek bisa bernyanyi lagu Indonesia Raya?"

$\cdots$

Data 7

(Irawan MN, 2015:132)

"Ndak, ndak!" ucap Nei. "Aku ndak mau pindah."

"Apa yang menahanmnu, Nei? Rustam telah tiada. Kau harus membesarkan sendiri buah hatimu. Di sini kau hidup sendiri. ayolah, mari kita pindah ke sana." (Irawan MN, 2015:75)

Data 5 adanya tindak tutur antara Nanjan dengan seseorang yang lebih tua yang disinyalir bersama orang tuanya yakni sang ibu. Pada data 5 dan data 7 referen kau menjadi awalan dalam sebuah kalimat. Dalam kedua data itu pula, penutur dan mitra tutur memiliki perbedaan dalam segi usia.

Data 8

"Jadi kau dukung anak itu untuk pindah, Cor?" Iskandar berkata.

Conelius menjawab, "Aku tak berkata seperti itu. Dan tolong perjelasan terlebih dahulu: kau bertanya padaku sebagai prajurit, atau sebagai rakyat yang hidup di perbatasan seperti ini...."

(Irawan MN, 2015:121)

$\underline{\text { Data } 9}$

"Pasar Entikong? Mane tu?"

"Kau belum pernah mendengarnya."

Siti Menggeleng.

"Suatu waktu, suatu saat, ku ajak kau ke sana. Itu pun kalau kau mau."

"Iya, aku nak!" teriak Siti seperti bocah kecil yang diajak main.

"Tapi, kau harus minta izin pada ayah dan ibumu," ucap Hamdan.

"Tentu saja, tapi..."

"Tapi apa?"

"Kalau aku pergi denganmu. Kau tak nak mengucilkanku kan?...."

(Irawan MN, 2015:211)

Data 10

"Aha, beruntung sekali aku bertemu denganmu, kawan. Kupikir tadi kau tidak di rumah." Ucap Felix.

"Aku tak berangkat. Ada pesanan yang harus segera selesai kukerjakan."

"Pesanan apa?"

"Kursi yang kau duduki itu."

"Oho, memang indah rupa bentuknya. Pastilah mahal harganya"

(Irawan MN, 2015:137)

Pada data 8, awalnya Iskandar menggunakan referen ini untuk merujuk kepada Cornelius. Hal serupa pun terjadi pada data 9 dan data 10. Baik penutur dan mitra tutur menggunakan referen kau sebentuk rujukan

Data 11 
"Dan, pemerintah Indonesia berteriak, Hai, manusia perbatasan! Jangan kau pindah ke Negeri Jiran. Jangan kau permalukan bangsamu. Sabarlah, nanti juga aku bangun kampungmu!"

(Irawan MN, 2015:179)

Data 11 merupakan sebuah wacana yang terdapat penggunaan deiksis persona orang kedua yakni kau. Bila diamati referen ini merujuk kepada seluruh masyarakat yang tinggal di perbatasan negara, sebab berdasarkan isi novel membahas tentang masalah kehidupan yang dialami oleh masyarakat perbatasan khususnya masyarakat Jagoi Babang.

Data 12

"Kalian pindahlah. Sekarang juga tidak apa-apa! Biarlah aku tinggal sendiri di sini. Kau, Imah, kalau kau ingin kawin lagi dengan orang Malaysia, terserah. Anak dan istri sama saja. Kalian memalukan bangsa!"

"Kenapa bapak ngomong seperti itu?" sang Ibu bertanya. "Tidak bisa seperti itu Pak. Kau tak ingat bagaimana kau dulu membawaku dari orang tuaku? Kau tak ingat, cinta kita telah membuatku berpisah dari orang tuaku?...."

(Irawan MN, 2015:291-292)

Data 13

"Kau menentangku?" Cornelius menantang.

"O, tidak-dengan bedil yang ada di tanganmu itu, tak akan ada yang berani menentangmu!"

Sipet berkata, "Pertama, kau prajurit di sini. Masalah ini, bukan masalahmu, ini masalah kami, warga Jagoi Babang. Kau bukan orang Jagoi Babang. Kedua, kau jangan memperkeruh suasana. Urusan kami bukan urusan tentara. Kau tak bisa seenaknya bertolak pinggang di sini."

(Irawan MN, 2015:284)

Bila diperhatikan pada isi tuturan di atas yakni tentang adanya perbedaan perdapat antara penutur dan mitra tutur. Diketahui bahwa Imah merupakan ibu dari Hamdan. Hal serupa pun terjadi dalam data 13 yang melibatkan Sipet, seorang pemuda Jagoi Babang bersama seorang penjaga perbatasan yakni Cornelius. Dalam tindak tutur di atas diketahui adanya selisih paham yang terjadi di antara keduanya.

\section{Deiksis Persona Orang Ketiga}

Data 1

....

"Juga tak ada hubungannya. Dia tetap tetua kampung kita."

"Maksudku, dia pasti menentang rencana kita."

"Bolehlah dia menentang-yang penting kita ajak semua orang untuk segera eksodus ke Malaysia."

(Irawan MN, 2015:85)

Data 2

"Jadi bagaimana?"

"Kita pasrahkan pada alam tentang apa yang akan terjadi. Kau tak perlu khawatir, aku akan berbicara dengan Nanjan dan para pemuda itu. Tetapi aku pun tak bisa memaksa dia untuk memilih seperti pilihanku. Biarlah warga 
sendiri yang menetapkan pilihan. Kau undanglah warga untuk berkumpul di sini secepatnya....

(Irawan MN, 2015:127-128)

Data 3

"Sukimin dan Parno yang bercerita. Juga Ampong, semua orang. Selama beberapa hari, Felix tak bekerja. Ternyata dia mendatangi rumah warga dan mengajak mereka untuk menolak ajakan kita. Ibuku sendiri didatanginya."

"Mau apa sebenarnya dia?" Nanjan bertaya.

"Selama ini, dia selalu bersama kita. Semua rencana yang kita buat, tak pernah kita sembunyikan darinya. Ulahnya menunjukkan dia menentang kita. Dia menantangku sekarang!"

(Irawan MN, 2015:147)

Dalam data 1 adanya tindak tutur antara Mamut bersama Nanjan. Dalam tindak tutur tersebut adanya penggunaan referen dia yang bila diperhatikan merujuk kepada seseorang yang bernama Pang Ukir. Hal serupa pula yang terjadi pada data 2. Tindak tutur dalam data tersebut melibatkan Pang Ukir dan Felix. Mereka pula menggunakan referen dia sebagai bentuk rujukan kepada seseorang yang tidak terlibat langsung dalam tindak tutur tersebut yakni Nanjan.

Data 3 ini yang menjadi rujukan daru referen dia yakni Felix.

Data 4

Para pemuda dusun Sinar Baru, Jagoi Babang kenal dengan semua prajurit. Yang bernama Herman, mereka pun sangat kenal. Herman tengah menatap tulisan di atas kertas ketika ia melihat Nanjan, Mamut, dan lain-lain menggotong tubuh lelaki itu.

“Dia tertembak kakinya!” seru Nanjan pada Herman. Si lelaki itu terus digotong masuk ke dalam rumah.

"Kami tak tahu. Kita temukan ia di perbatasan."

(Irawan MN, 2015:41-42)

Orang yang menjadi rujukan dalam data 4 ini, tidak terlibat langsung dalam tindak tutur tersebut. Hal ini dikarenakan kondisi fisik dari yang bersangkutan sehingga dirinya tidak mampu untuk berkomunikasi

$\underline{\text { Data } 5}$

Namanya Rustam. Dia berasal dari Jambi, bersuku Melayu dan beragama Islam.

Setahun lamanya Rustam di tugaskan di Pos Perbatasan Entikong....

(Irawan MN, 2015:71-72)

Data 6

Adalah Hamdan, pemuda Melayu, yang berteman baik dengan Nanjan dan

Mamut. Ia juga berkawan akrab dengan Parno dan Sukimin...."

(Irawan MN, 2015:22)

Data 7

Sukimin juga seorang muslim. Hanya saja, kadang-kadang ia lupa untuk mengerjakan salat. Celakanya. Kelupaannya sering daripada ingatnya. Tetapi dia adalah pemilik hati yang cukup mulia....

(Irawan MN, 2015:89)

Bila diperhatikan pada ketiga data di atas merupakan perkenalan tokoh-tokoh yang telibat dalam novel Kidung Rindu di Tapal Batas yakni Rustam , Hamdan, dan Sukimin. Pengarang menggunakan referen dia dan ia sebagai bentuk rujukan kepada 
tokoh-tokoh tersebut yang tentunya tokoh tersebut disematkan sebagai bentuk subjek, sehingga kedua referen ini boleh untuk digunakan.

Data 8

Cornelius memperhatikan lelaki itu dengan seksama. Jantungnya berdetak kencang. Ia membisiki sesuatu pada Iskandar. Rekan- rekan prajurit yang lain pun segera mengangguk.

(Irawan MN, 2015:36)

Data 9

Tak mungkinlah bagi Nei untuk terus menerus mengharapkan adanya santunan atau belas kasihan. Sebagai perempuan asli Dayak dan tinggal digaris perbatasan, $i a$ tidak tahu apakah masih ada jatah uang pemerintah terhadapnya sebagai istri almarhum seorang tentara....

(Irawan MN, 2015:77)

Data 10

Mamut lantas membeberkan perkembangan informasi yang telah didapat dari berbagai sumber. Ia mencontohkan bagaimana wilayah-wilayah di perbatasan sangat bergantung kepada negeri tetangga.

(Irawan MN, 2015:108)

Data 11

Setelah berdiskusi secara tertutup dengan otoritas perbatasan dan TNI, Jokowi tidak segan-segan memanjat pos menara tertinggi di pulau Sebantik. Ia pun berbicang dengan dua anggota TNI AL yang berjaga-jaga selama 24 jam penuh di atas menara itu.

(Irawan MN, 2015:192)

Keempat data di atas merupakan sebuah penggambaran tentang situasi yang dialami oleh setiap tokoh yang terlibat dalam cerita dalam novel. Pengarang dalam hal ini bertindak sebagai penutur, merujuk para tokoh dengan menggunakana referen ia. Pengarang menceritakan keadaan yang dialami para tokoh dengan tujuan agar para pembaca yang dalam hal ini bertindak sebagai mitra tutur dapat lebih memahami maksud serta isi dari novel.

Data 12

"Padahal, kakekmu tadinya tak mau diajak pindah," imbuh sang ibu. "Tapi mau bagaimana lagi? Kakekmu sangat mencintainya. Ia akhirnya membuat kesepakatan dengan nenekmu: Baiklah, kita boleh pindah di sini. Aku mau jadi warga negara ini, asalkan anak-anak kita tetap tinggal di Jagoi Babang."

$\underline{\text { Data } 13}$

(Irawan MN, 2015:68)

Siti Nur Azizah, namanya. Dia putri Serawak asli. Tentu saja, dia seorang warga Malaysia. Saya tidak ingin menceritakan kisah cinta saya dengannya karena itu tidak penting untuk didengar saudara semua...."

(Irawan MN, 2015:275)

Data 12 bila diamati yang bertindak menjadi penutur yakni ibu, sedangkan sebagai mitra tutur yakni sang anak. Ibu menggunakan referen ia sebagai bentuk rujukan kepada sang kakek. Hal yang sama pun terjadi dalam data 13 saat Hamdan bertindak sebagai penutur dan mitra tutur yakni semua orang yang mendengar cerita dari Hamdan serta yang menjadi acuan dalam penggunaan referen dia adalah Siti Nur Azizah.

\section{$\underline{\text { Data } 14}$}


"Kabar yang aku dapatkan," jawab Sipet, "di beberapa wilayah, pemerintah Malaysia merasa prihatin dengan kondisi warga. Malaysia menawarkan bantuan listrik, juga pembangunan jalan. Jikalau pemerintah Indonesia bersedia, jalanjalan di perbatasan itu akan dibangun oleh pemerintah Malaysia merasa prihatin. Perhatian itu, menurutku, bisa kita artikan sebagai imbauan agar masyarakat lebih memilih ia yang memperhatikan kehidupannya...."

(Irawan MN, 2015:179)

Data 15

"Garuda ini-kalian tahu-selalu ada di dada ini. wara merah-putih itu, menjadi warna darahku. Dapatkah kalian melihat betapa air mata-ku berdarah-darah, menyaksikan merah-putih yang semakin kusam berkibar-kibar? Lihatlah bendera Malaysia di sana: Ia berkibar cemarlang di puncuk- puncuk galah yang tinggi, di atas tanah yang makmur, di atas atap-atap penduduk yang hidup bahagia...."

(Irawan MN, 2015:104)

Kedua data diatas terbilang cukup menarik, sebab yang menjadi rujukan dalam referen dia dan ia bukanlah laki-laki dan perempuan melainkan sebuah sesuatu atau sebuah benda. Hal semacam ini tentu saja bukan hal baru dalam penggunaan deiksis persona orang ketiga, sebab pada hakikatnya penggunaan dari deiksis persona orang ketiga tidak selamanya dan harus digunakan untuk merujuk orang.

\section{Deiksis Tempat}

\section{Penggunaan Referen di sini}

\section{Data 1}

.... upacara ini pun dihadiri oleh dua suku lain yang ada di Jagoi Babang. Benar bahwa perayaan ini adalah perayaan khusus masyarakat Dayak, tetapi di sini tinggal pula warga dari suku Melayu dan Jawa....

(Irawan MN, 2015:21)

Data 2

Seperti yang diceritakan oleh sang ibu sendiri, ketika kakek dan neneknya pindah, sang ibu ditinggal sendiri di sini.

"Jika ibu tidak bertahan di sini," lanjut sang ibu, "kau tak akan pernah lahir. Semua orang Dayak boleh tak mengakui kenyataan ini: Ayahmu adalah seorang tentara.

(Irawan MN, 2015:71) 
$\underline{\text { Data } 3}$

…

"Iya, berita-kita dor-doran dengan askar Diraja Malaysia. Kamu siapa sebenarnya? Mengapa bisa sampai di sini? Bikin repot dan kisruh dengan pemerintah Malaysia!"

Wajah Hasyim menjadi layu.

(Irawan MN, 2015:55-56)

Data 4

"Di sini, semua serba mudah," begitu ujar ibunya Nanjan saat-saat ia bercerita tentang kehidupan neneknya....

(Irawan MN, 2015:68)

Data 5

Malam ini, tak hanya rumah Pang Ukir yang ramai. Rumah Nanjan pun ramai pula. Para pemuda Jagoi Babang itu berkumpul di sini....

(Irawan MN, 2015:257)

Berdasarkan isi tuturan dalam data pertama menunjukan bahwa dalam data 1 dan 2 yang menjadi rujukan untuk referen di sini adalah Jagoi Babang, sedangkan dalam data 3 ini referen di sini mengacu pada sebuah tempat yakni pos perbatasan. sedangkan pada data 4, Malaysia menjadi rujukan dalam penggunaan referen di sini. Terakhir pada data 5 referen di sini digunakan untuk merujuk terhadap salah satu rumah warga Jagoi Babang yakni Nanjan.

\section{Penggunaan Referen di sana}

Data 1

Hamdan pun segera menceritakan Jagoi Babang. Tentang alamnya, jalannya, hutannya, jembatannya, pos perbatasan, para tentara, kehidupan warganya, suku-suku yang tinggal di sana, dan seterusnya....

Data 2 (Irawan MN, 2015:214)

Di sana, listrik semakin berpendar-pendar. Rumah-rumah warga di Kuching rata-rata sudah bagus. Dan pasar selalu saja ramai. Bahkan makin lama makin ramai. Yang paling penting: segala kebutuhan hidup tersedia berlimpah dan mudah didapatkan.

Di Jagoi Babang?

Ah...

(Irawan MN, 2015:80)

Data 3

"Tembak saja!" ucap Cornelius. "Setelah aku mati, bedah dadaku, dan lihatlah jiwa prajurit tertanam di sana aku bicara bukan sebagai prajurit tetapi sebagai rakyat biasa...."

(Irawan MN, 2015:121) 


\section{$\underline{\text { Data } 4}$}

.....Selama seminggu itu, hari minggu adalah hari penghibur bagi mereka. Pasar adalah tempat mencari hiburan itu, di mana rasa lelah dan letih bergelut dengan sawit dan pohon-pohonnya bisa disirnakan di sana....

(Irawan MN, 2015:208-209)

\section{Data 5}

“.....Kenapa, dulu orang Indonesia lebih memilih menjadi warga negara Belanda, Malaysia, atau Suriname? Kalian tau Suriname. Oh, di antara kalian mungkin baru pertama kali mendengar nama itu. Ketahuilah di sana hampir semua warganya keturunan Jawa....."

(Irawan MN, 2015:271)

Referen di sana pada data 1 mengacu pada sebuah tempat yang berdasarkan data di atas adalah Jagoi Babang. Kemudian dalam data 2 referen "di sana" mengacu pada sebuah tempat yang berdasarkan data di atas adalah negara Malaysia. Dalam data 3, referen deiksis tempat mengacu pada sebuah tempat yang berdasarkan data di atas adalah sebuah dada. sedangkan data data 5 referen ini mengacu pada pasar Serikin yang berada di Malaysia. Terakhir data 6 referen di sana mengacu pada sebuah tempat yang berdasarkan data di atas adalah Suriname.

\section{Deiksis Waktu}

\section{Data 1}

Hari ini memang hari yang sangat istimewa bagi warga Jagoi Babang. Sekarang bukan tanggal 17 Agustus dan warga kampung ini tidak sedang memeriahkan Agustusan. Tetapi ketahuilah mereka sedang mengadakan ritual Hari Gawai dan setiap tanggal 1 Juli....

(Irawan MN, 2015:6)

Data 1. Sama halnya seperti data 1 terdapat penggunaan referen "hari ini" atau sebuah penanda waktu yang sedang berlangsung. Muhyudin (2019:48) dalam penelitiannya yang berjudul deiksis dalam novel Daun yang Jatuh Tak Pernah Membenci Angin karya Tere Liye dan skenario pembelajarannya di SMA. Inti penelitian tersebut yakni deiksis waktu adalah ketegori deiksis yang digunakan untuk merujuk waktu yang dimaksud dalam tuturan.

Data 2

“Aman!” ucap Iskandar kepada rekan-rekannya itu. "Terkendali. Mereka sudah pergi dari perbatasan. Tinggal menunggu berita nanti malam!"

"Berita....? Maksudnya?" Hasyim, dengan wajah yang kembali diliputi ketegangan pun bertanya.

"Iya, berita-kita dor-doran dengan askar Diraja Malaysia. Kamu siapa sebenarnya? Mengapa bisa sampai di sini? Bikin repot dan kisruh dengan pemerintah Malaysia!"

Wajah Hasyim menjadi layu.

(Irawan MN, 2015:55-56)

Referen waktu nanti malam yang diucapkan oleh Iskandar merupakan sebuah penanda bahwa peristiwa tersebut belum terjadi atau akan terjadi. Diketahui bahwa para tentara penjaga perbatasan negara itu sedang dirundung kecemasan tentang apa yang baru saja terjadi di daerah perbatasan.

(Irawan MN, 2015:11) 
Data 3

"Itulah kenapa kakek-monyangmu menjadi orang Malaysia," begitu kata kakekkakek kepada cucu-cucunya. "Dulu, kita tak berpisah. Borneo adalah Borneo.

Tak ada Malaysia dan Indonesia. Tak ada garis pemisah, patok-patok"

(Irawan MN, 2015:64)

Pada data 3 penutur diketahui menggunakan referen $d u l u$. Referen waktu $d u l u$ atau dahulu merupakan sebuah penanda bahwa peristiwa tersebut telah terjadi dalam kurun waktu yang sudah sangat cukup lama.

Data 4

Hamdan ingin membeli kain untuk ibunya. Kemarin hari sabtu dan ia telah menerima bayaran kerja salama seminggu. Hari ini hari minggu dan ia harus pergi ke pasar Serikin untuk belanja barang-barang juga membeli kain untuk ibunya itu.

(Irawan MN, 2015:203)

Data 4 menunjukkan adanya penggunaan deiksis waktu yakni dengan referen kemarin. Bila diartikan kata kemarin merupakan bentuk waktu yang telah terjadi. Orang-orang bisanya menggunakan kata ini untuk merujuk kepad waktu yang telah terjadi namun belum terlalu lama seperti baru terjadi sehari sebelum terjadinya tindak tutur.

\section{Data 5}

"Ini hari apa?" Nanjan bertanya.

"Minggu. Apa kau lupa?"

"Kenapa lagu itu diputar-putar terus?"

"Lagu mana?"

"Itu dengar!"

"Oooh itu suara Siti Nurhaliza!" seru Hamdan.

(Irawan MN, 2015:202)

Data di atas menunjukkan adanya penggunaan deiksis waktu yakni dengan referen minggu. Minggu merupakan hari pertama dalam sepekan. Referen ini menunjukkan waktu kejadian dari tindak tutur di atas terjadi pada hari minggu.

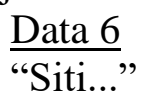

"Iya, Abang."

"Minggu depan, maukah kau bertemu denganku?"

"Tentu saja, Abang. Ngape Abang bertanya macam ni?"

"Tidak Siti," jawab Hamdan. "Maksudku, kita bertemu dengan cara seperti yang aku harapkan.”

(Irawan MN, 2015:218)

Berdasarkan isi ditemukan adanya penggunaan deiksis waktu yakni dengan referen minggu depan. Minggu dalam penanggalan kalander merupakan hari pertama dalam sepekan. Berbeda dengan data keenam, referen minggu depan merupakan referen yang menunjukkan waktu yang belum terjadi.

Data 7

.... "Bang, besok Abang akan kita antar ke Entikong, Abang tidak perlu gelisah..."

Dicekat ketidaksangkaan, Hasyim tak bisa membuka mulutnya.

(Irawan MN, 2015:303) 
Data di atas menunjukkan adanya penggunaan deiksis waktu yakni dengan referen besok. Referen besok yang diucapkan oleh Iskandar merupakan sebuah penanda bahwa tuturan yang ia ucapan kepada Hasyim merupakan sebuah rencana yang akan dilaksanakan satu hari setelah tindak tutur diujarkan.

\section{PENUTUP}

Deiksis terdiri dari 3 jenis utama yakni deiksis persona, deiksis tempat dan deiksis waktu. Deiksis persona terbagi dalam 3 bagian yakni deiksis persona orang pertama, deiksis persona orang kedua, serta deiksis persona orang ketiga. Berikut ini merupakan bentuk-bentuk referen yang digunakan dalam novel Kidung Rindu di Tapal Batas karya Aguk Irawan MN.

Pertama, deksis persona yang terbagi atas deiksis persona orang pertama menggunakan bentuk referen saya. yang merujuk kepada kepada Iskandar, Ibu, Ahmad Ibrahim, Nanjan, seorang lelaki, Felix dan Hasyim, sedangkan deiksis persona orang kedua menggunakan bentuk referen kau merujuk kepada Parno, Mamut, Iskandar, Rustam, Nanjan, Felix Nei, Cornelius, Siti, Kumar, Masyarakat Jagoi Babang, Imah, dan Sipet dan deiksis persona orang ketiga menggunakan referen dia, ia yang merujuk kepada Pang Ukir, Nanjan, Felix, orang yang tidak dijelaskan, Rustam, Hamdan, Sukimin, Cornelius, Nei, Mamut, Jokowi, kakek, Siti Nur Azizah, pemerintah Malaysia dan sebuah bendera. Kedua, deiksis tempat menggunakan referen di sini dan di sana. Referen di sini yang merujuk terhadap Jagoi Babang, pos Perbatasan, Malaysia dan rumah Nanjan dan pengunaan referen di sana merujuk terhadap Jagoi Babang, Malaysia,dada manusia, pasar Serikin dan Suriname. Ketiga, deiksis waktu menggunakan referen hari ini, nanti malam, dulu, kemarin, hari minggu, minggu depan, dan besok. Referen-referen ini mengacu pada waktu peristiwa tutur terjadi.

\section{DAFTAR PUSTAKA}

Aminuddin. 2008. Semantik Pengantar Studi Tentang Makna. Bandung: Sinar Baru Algensindo.

Chaer, Abdul. 2012. Linguistik Umum. Jakarta: Rineka Cipta.

Hermaji, Bowo. 2019. Teori Pragmatik. Yogyakarta: Magnum Pustaka Utama.

Muhyidin, Asep. 2019. Deiksis Dalam Novel Daun yang Jatuh Tak Pernah Membenci Angin Karya Tere Liya dan Skenario Pembelajarannya di SMA dalam jurnal Universitas Sultas Ageng Titayasa. Vol. 17. No. 1.

Wicaksono, Andri. 2014. Pengkajian Prosa Fiksi. Yogyakarta: Garudhawaca.

Yule, George. 2014. Pragmatics (Pragmatik). Wahyuni Indah Fajar (penerjemah). Yogyakarta: Pustaka Pelajar. 